\title{
Cost-analysis and quality of life after laparoscopic and robotic ventral mesh rectopexy for posterior compartment prolapse: a randomized trial
}

\author{
J. Mäkelä-Kaikkonen ${ }^{1,2} \cdot$ T. Rautio ${ }^{1,2} \cdot$ A. Ohinmaa ${ }^{3} \cdot$ S. Koivurova ${ }^{4} \cdot$ P. Ohtonen ${ }^{1,2} \cdot$ H. Sintonen ${ }^{5} \cdot J_{\text {. Mäkelä }}^{1,2}$
}

Received: 6 February 2019 / Accepted: 15 April 2019 / Published online: 8 May 2019

(c) The Author(s) 2019

\begin{abstract}
Background The aim of this study was to assess, whether robotic-assistance in ventral mesh rectopexy adds benefit to laparoscopy in terms of health-related quality of life (HRQoL), cost-effectiveness and anatomical and functional outcome. Methods A prospective randomized study was conducted on patients who underwent robot-assisted ventral mesh rectopexy (RVMR) or laparoscopic ventral mesh rectopexy (LVMR) for internal or external rectal prolapse at Oulu University Hospital, Finland, recruited in February-May 2012. The primary outcomes were health care costs from the hospital perspective and HRQoL measured by the 15D-instrument. Secondary outcomes included anatomical outcome assessed by pelvic organ prolapse quantification method and functional outcome by symptom questionnaires at 24 months follow-up.

Results There were 30 females (mean age 62.5 years, SD 11.2), 16 in the RVMR group and 14 in the LVMR group. The surgery-related costs of the RVMR were 1.5 times higher than the cost of the LVMR. At 3 months the changes in HRQoL were 'much better' (RVMR) and 'slightly better' (LVMR) but declined in both groups at 2 years (RVMR vs. LVMR, $p>0.05$ ). The cost-effectiveness was poor at 2 years for both techniques, but if the outcomes were assumed to last for 5 years, it improved significantly. The incremental cost-effectiveness ratio for the RVMR compared to LVMR was €39,982/quality-adjusted life years (QALYs) at 2 years and improved to $€ 16,707 /$ QALYs at 5 years. Posterior wall anatomy was restored similarly in both groups. The subjective satisfaction rate was $87 \%$ in the RVMR group and $69 \%$ in the LVMR group $(p=0.83)$.

Conclusions Although more expensive than LVMR in the short term, RVMR is cost-effective in long-term. The minimally invasive VMR improves pelvic floor function, sexual function and restores posterior compartment anatomy. The effect on HRQoL is minor, with no differences between techniques.
\end{abstract}

Keywords Ventral mesh rectopexy $\cdot$ Laparoscopic $\cdot$ Robotic $\cdot$ Cost-analysis $\cdot$ Quality of life

\section{Introduction}

J. Mäkelä-Kaikkonen

johanna.makela-kaikkonen@ppshp.fi

1 Division of Gastroenterology, Department of Surgery, University Hospital of Oulu, PO Box 21, 90029 Oulu, Finland

2 Center of Surgical Research, Medical Research Center, University of Oulu, Oulu, Finland

3 School of Public Health, University of Alberta, Edmonton, $\mathrm{AB}$, Canada

4 Department of Obstetrics and Gynecology, University Hospital of Oulu, Oulu, Finland

5 Department of Public Health, University of Helsinki, Helsinki, Finland
External rectal prolapse (ERP) and internal rectal prolapse (IRP) with symptoms of obstructed defecation and/or fecal incontinence are debilitating conditions resulting in impairment of the patients' quality of life [1]. Laparoscopic ventral mesh rectopexy (LVMR) is proposed as the treatment of choice for ERP and is also increasingly performed to treat symptomatic IRP in selected patients [2-6]. Robot-assisted surgery offers an alternative to laparoscopy in rectopexy operations with its acknowledged technical advantages, which may be of benefit when operating in confined pelvic space [7-9]. Between 2012 and 2015 the largest increase in robot use in colorectal surgery in the United States happened in robotic rectopexy which increased from 15 to $27 \%$ with contemporaneous $12 \%$ decrease in open rectopexies 
and overall increase in laparoscopic approaches from 30 to $32 \%$ [10].

The role of robot-assisted laparoscopy in treating posterior pelvic floor dysfunction is undetermined, based on current evidence of non-randomized relatively small comparative series of rectopexy operations [11-13]. It is not known, if robotic ventral mesh rectopexy (RVMR) offers improvements in medical care and operative outcomes in the form of better anatomical and functional results, improved health-related quality of life (HRQoL) and a reduced recurrence rate. A systematic review and meta-analysis of 6 studies and 340 patients showed less intraoperative bleeding, lower incidence of postoperative complications and shorter hospital stay for RVMR compared with LVMR, but found no differences in rates of recurrence, conversion or reoperation [14]. Major drawbacks limiting robot-use are increased cost and longer operating times [14]. The cost-effectiveness of robot-use in rectopexy operations has not been evaluated using cost-utility analysis. Health care decision makers need more information from economic evaluations to show whether implementing the new expensive robotic technology is providing extra value for the society. The aim of this study was to evaluate the incremental cost-effectiveness in terms of cost per quality-adjusted life year (QALY) gained of RVMR compared to LVMR using hospital perspective and secondarily, to compare the effect of RVMR and LVMR for posterior compartment procidentia on pelvic floor anatomy and function in the long-term.

\section{Materials and methods}

This study is a part of a prospective randomized controlled series comparing RVMR and LVMR operations registered in Current Controlled Trials, ISRCTN88884232. The study protocol has been approved by the Ethics Committee of the Oulu University Hospital. Within a concept of pilot study, we aimed to include 30 patients in the trial. Thirty-three consecutive female patients who were diagnosed with ERP or recto-anal IRP with or without entero/rectocele combined with symptoms of obstructive defecation and/or fecal incontinence were recruited to the study between February and May 2012. All patients signed written informed consent. The randomization method is explained in our previous report of short-term results at 3-month follow-up [15]. Allocation and follow-up are displayed in Fig. 1. Preoperative diagnostics included clinical anorectal examination, pelvic examination, colonoscopy, and magnetic resonance (MR)-defecography.

\section{Surgical technique}

The robotic operations were performed by three surgeons and in addition fourth surgeon participated in laparoscopic operations. Our surgical technique follows the protocol described by D'Hoore and Penninckx [3], with slight modifications described earlier [16]. The rectovaginal space was dissected deep to the levator plane with harmonic scalpel. A single polypropylene mesh (Parietex ${ }^{\mathrm{TM}}$, size $3 \mathrm{~cm} \times 20 \mathrm{~cm}$; Covidien, Dublin, Ireland) was fixated caudally with two resorbable sutures through the pelvic floor using an endofascial closing device and thereafter anteriorly to the rectum and to the apex of the vagina with 6-7 pairs of non-absorbable sutures. For the suspension to the sacral promontory spiral attachments were used (Pro-Tack ${ }^{\mathrm{TM}}$ Fixation Device, Covidien) and peritoneum was closed over the mesh with continuous suture with $15-\mathrm{cm}$ long V-Loc ${ }^{\mathrm{TM}}$ (Covidien). The RVMR were performed following the same protocol with $\mathrm{Si}$ Da Vinci Surgical System (Intuitive Surgical Inc, Sunnyvale, CA, USA). For the robotic procedures we used side docking and five trocar placements. The patients were blinded to the operative technique.

\section{Effectiveness measurement}

All patients had standardized evaluation preoperatively and at 3- and 24-month follow-up. The HRQoL was measured by the generic preference-based 15D instrument [17]. The HRQoL of patients were compared with that of a sample of general Finnish female population derived from a representative population survey, Health 2011 [33]. The disease-specific instruments included the Finnish translations of the Pelvic Floor Distress Inventory (PFDI-20), and the Pelvic Floor Impact Questionnaire 7 (PFIQ-7) [18], the Wexner score for anal incontinence [19] and the Obstructed Defecation Syndrome score (ODS score) [20]. POP-Q measurements (Pelvic Organ Prolapse Quantification) [21] were obtained in supine lithotomy position during maximal Valsalva.

\section{Cost-analysis}

The cost-analysis includes the costs of surgical intervention, hospitalization and the cost of reoperations using the same method as original surgery, and other major complications. The costs of surgical intervention includes the capital costs of robot- and laparoscopy instrument use and the operating time of the personnel measured in minutes and multiplied by personnel's salary including benefits from the hospital accounting. The capital cost of robot and laparoscopy equipment was divided over 10 years using $2 \%$ hospital specific interest rate and calculated per procedure. The cost of postoperative hospitalization including medication costs were extracted from hospital records. Considering the small study sample, we used 


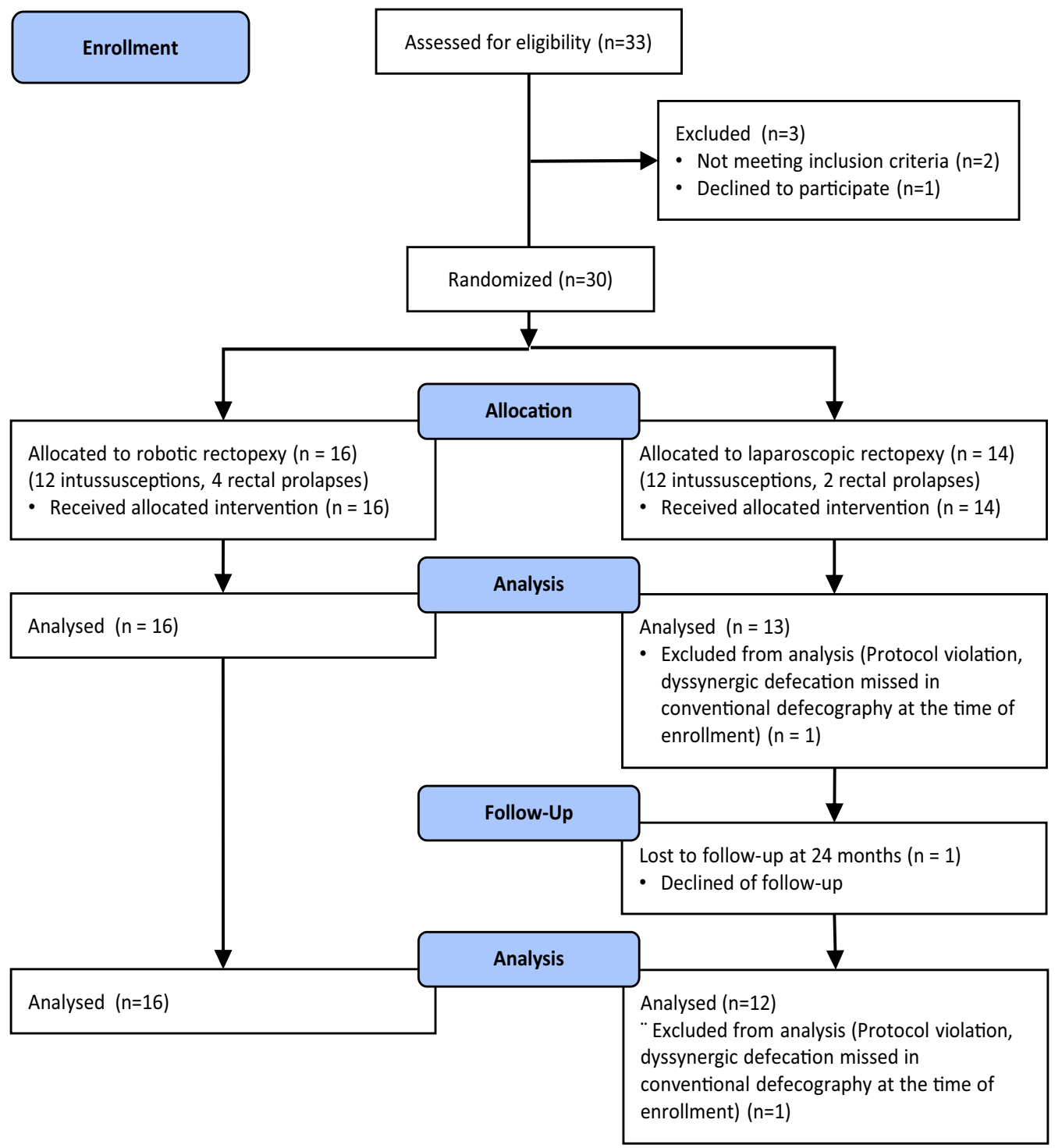

Fig. 1 Flow chart of study

reoperation rates from 2007 to 2013 to estimate re-surgery rate for RVMR (2.2\%) and LVMR (11.6\%). The lost productivity due to sick leave and possible additional postoperative health and social services were surveyed during the follow-up visits. All costs are reported as Euros and were originally valued at the 2012 price level and then inflated to the 2017 price level using the price index of public health care [22]. The costing details are in the footnote of Table 4.

\section{Economic analysis}

Economic analysis was done using incremental cost-effectiveness analysis [23]. The HRQoL outcomes were assessed using the $15 \mathrm{D}$ instrument that provides a preference-based single index value for each measurement, before operation, and 3 and 24 months postoperatively. Quality-adjusted life years (QALYs) gained after surgery were estimated using individual level 15D scores at baseline to represent no surgery option and comparing it to estimated area below curve during 2-year follow-up after surgery and estimating the difference between these two lines. In the final analysis incremental cost per incremental QALY ratio for the RVMR compared to LVMR was estimated for 2 years as the base case, and for 5 years assuming constant annual QALY gain and no additional incremental costs (same healthcare services).

We used 3\% discount rate to calculate 2 and 5 years QALY results. The number of robotic surgeries (284/year) 


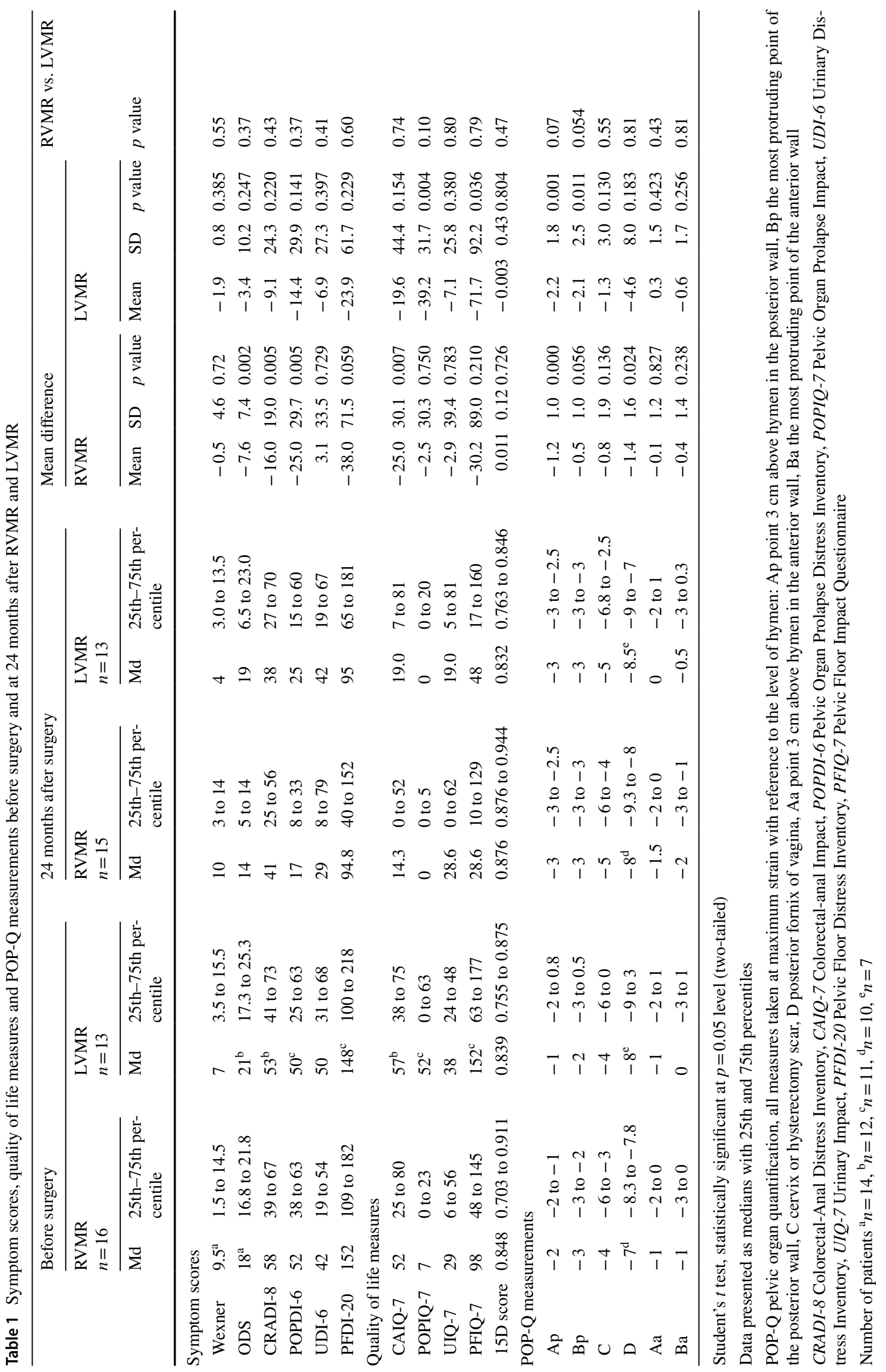


Table 2 POP-Q stage changes after RVMR and LVMR surgery

\begin{tabular}{|c|c|c|c|c|c|c|c|}
\hline Compartment & Before surgery & 3 months & 24 months & $\begin{array}{l}p \text { value }^{\mathrm{a}} \\
3 \text { months }\end{array}$ & $\begin{array}{l}p \text { value }^{\mathrm{b}} \\
3 \text { months }\end{array}$ & $\begin{array}{l}p \text { value }^{\mathrm{a}} \\
24 \text { months }\end{array}$ & $\begin{array}{l}p \text { value }^{\mathrm{b}} \\
24 \text { months }\end{array}$ \\
\hline \multicolumn{8}{|c|}{ Posterior wall stage $(0 / 1 / 2 / 3)$} \\
\hline All & $4 / 10 / 13 / 2$ & $14 / 14 / 1 / 0$ & $16 / 12 / 0 / 0$ & 0.186 & $<0.001$ & 0.667 & $<0.001$ \\
\hline Robotic & $2 / 7 / 7 / 0$ & $8 / 7 / 1 / 0$ & $8 / 7 / 0 / 0$ & & 0.006 & & 0.004 \\
\hline Laparoscopic & $2 / 3 / 6 / 2$ & $6 / 7 / 0 / 0$ & $8 / 5 / 0 / 0$ & & 0.007 & & 0.001 \\
\hline \multicolumn{8}{|c|}{ Apex stage $(0 / 1 / 2 / 3)$} \\
\hline All & $9 / 14 / 4 / 2$ & $13 / 14 / 2 / 0$ & $11 / 16 / 1 / 0$ & 0.119 & 0.020 & 0.841 & 0.156 \\
\hline Robotic & $5 / 10 / 1 / 0$ & $6 / 10 / 0 / 0$ & $6 / 9 / 0 / 0$ & & 1.000 & & 1.000 \\
\hline Laparoscopic & $4 / 4 / 3 / 2$ & $7 / 4 / 2 / 0$ & $5 / 7 / 1 / 0$ & & 0.031 & & 0.180 \\
\hline \multicolumn{8}{|c|}{ Anterior wall stage $(0 / 1 / 2 / 3)$} \\
\hline All & $3 / 7 / 16 / 3$ & $2 / 12 / 15 / 0$ & $2 / 11 / 15 / 0$ & 0.640 & 0.109 & 0.396 & 0.273 \\
\hline Robotic & $2 / 3 / 11 / 0$ & $1 / 8 / 7 / 0$ & $2 / 6 / 7 / 0$ & & 0.375 & & 0.375 \\
\hline Laparoscopic & $1 / 4 / 5 / 3$ & $1 / 4 / 8 / 0$ & $0 / 5 / 8 / 0$ & & 0.375 & & 0.750 \\
\hline
\end{tabular}

${ }^{a}$ Robot-assisted and laparoscopic groups tested using the Mann-Whitney $U$ test

${ }^{\mathrm{b}}$ Wilcoxon signed-rank test, based on positive ranks was based on our hospital 2015-2017 surgery numbers. The main analysis was done using the operating hospital perspective, since the pre- and postoperative health care services outside the hospital were estimated to be the same.

Sensitivity analysis was done using one way and multiway sensitivity analysis for key cost variables, like operation time, equipment lifetime of 7 years, and number of reoperations, 200 operations/year, and 0\% discount rate for QALY.

\section{Statistical analysis}

Statistical analysis was performed using SPSS for Windows (released 2015, version 23.0. IBM, Armonk, NY, USA). Differences between the study groups were analyzed using Student's $t$ test for continuous data and Chi-squared test or Fisher's exact test for categorical data. If both preoperative and postoperative values were calculated, then first the difference between the preoperative and postoperative value was calculated (change) and the between group comparison of the changes was compared using a $t$ test (continuous variables), Mann-Whitney test (semi-continuous variables) or Fisher's exact test (categorical variables). Variables with more than two repeated measurements were analyzed using Linear Mixed Model (LMM) assuming random subject effect. The covariance pattern for LMM was chosen according to Akaike's information criteria. $p$ values reported for LMM are p-time, indicating change over time, $\mathrm{p}$-group indicating average between group difference, and $p$-time $\times$ group indicating interaction between time and group. A $p$ value of less than $<0.05$ was considered statistically significant.

\section{Results}

\section{Clinical effectiveness}

From 30 female patients (62.5 years, SD 11.2) operated on, 16 patients (4 ERP and 12 IRP) had RVMR and 14 patients (2 ERP and 12 IRP) LVMR. Table 1 summarizes the anatomical, functional and condition-specific quality of life outcomes at baseline and at 24-month follow-up. An improvement was seen in pelvic floor distress inventory scores (PFDI) and specifically in the colorectal-anal (CRADI) and pelvic organ prolapse (POPDI) subscales. An overall improvement in obstructed defecation was achieved in $84.6 \%$ of RVMR patients and in $41.7 \%$ of LVMR patients. In total, $48.1 \%$ of patients reported fecal incontinence before surgery (RVMR 50\%, LVMR 46.2\%) with no significant improvement in Wexner scores at the follow up. Table 2 summarizes the POP-Q stage changes after the operation. All patients in both study groups had maintained the posterior wall stage $\leq 1$. No differences were found either in the anatomical or functional parameters between the RVMR and LVMR groups (Fig. 2). Prior to the 24-month follow-up, one patient in LVMR group had been treated with RVMR for ERP recurrence, thereby giving an $8 \%$ failure rate for the LVMR group compared to no reoperations in the RVMR group.

\section{Health-related quality of life}

Figures 2 and 3 show the mean 15D scores at different time points. At baseline the study population had significantly 

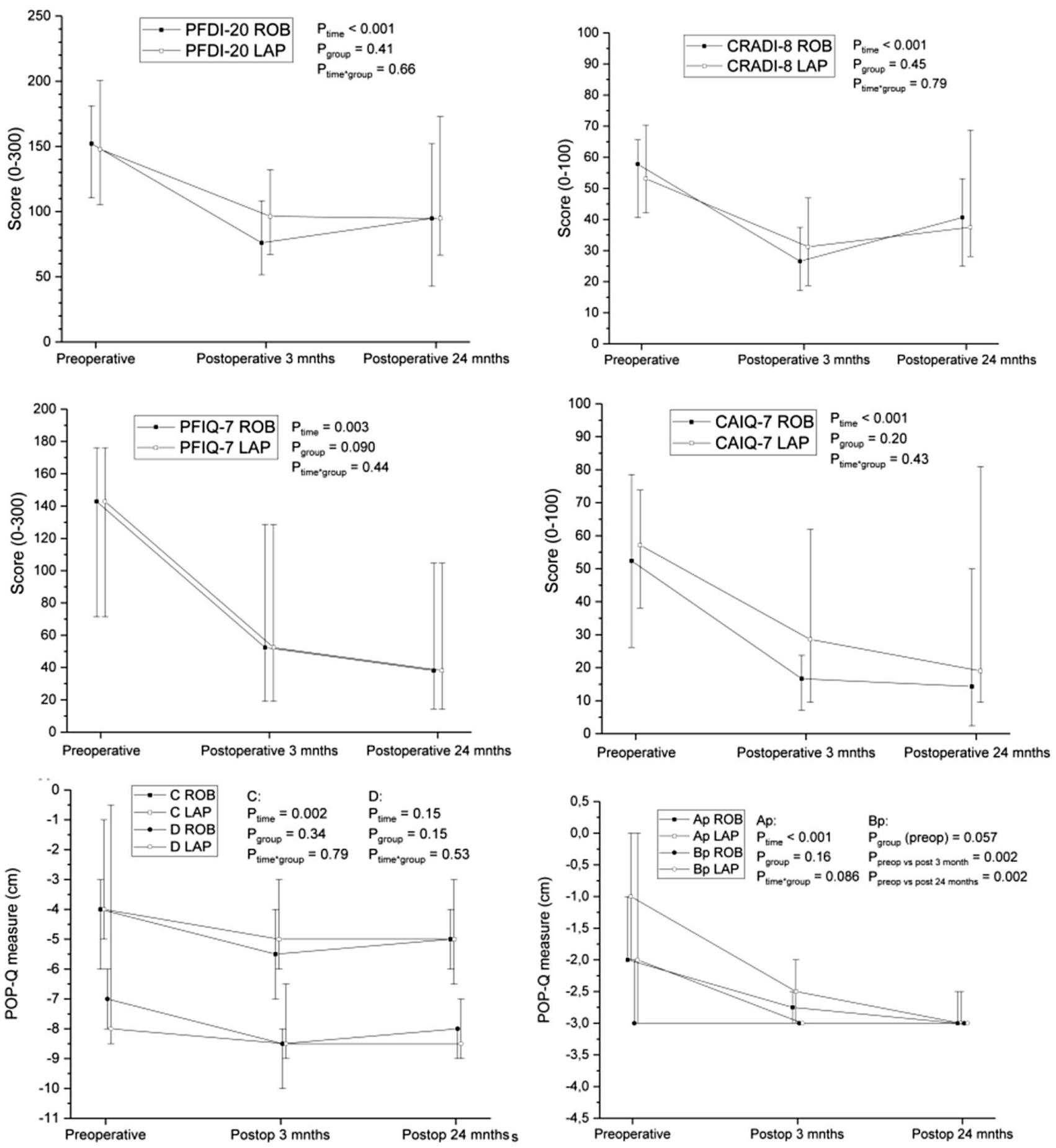

Fig. 2 The comparison of changes in median symptom scores, symptom-specific QoL scores and posterior wall POP-Q measurements for the RVMR and LVMR groups. PFDI-20 Pelvic Floor Distress Inventory, CRADI-8 Colorectal-Anal Distress Inventory, PFIQ-7 Pelvic Floor Impact Questionnaire, CAIQ-7 Colorectal-anal Impact Ques-

reduced scores on the dimensions of excretion and discomfort/symptoms compared to general population (Fig. 3a, b). At 3 months the dimensions of excretion, sexual activity and discomfort/symptoms were somewhat improved, but by

tionnaire, $P O P-Q$ pelvic organ quantification, all measures taken at maximum strain with reference to the level of hymen: Ap, point $3 \mathrm{~cm}$ above hymen in the posterior wall, Bp the most protruding point of the posterior wall. Data presented as medians with 25 th and 75 th percentiles

24 months the HRQoL scores were back to the original or slightly higher levels $(p=\mathrm{NS})$ than at baseline except for sexual activity that remained at a higher level $(p=\mathrm{NS})$. At 3 months, the mean 15D score had improved from baseline 


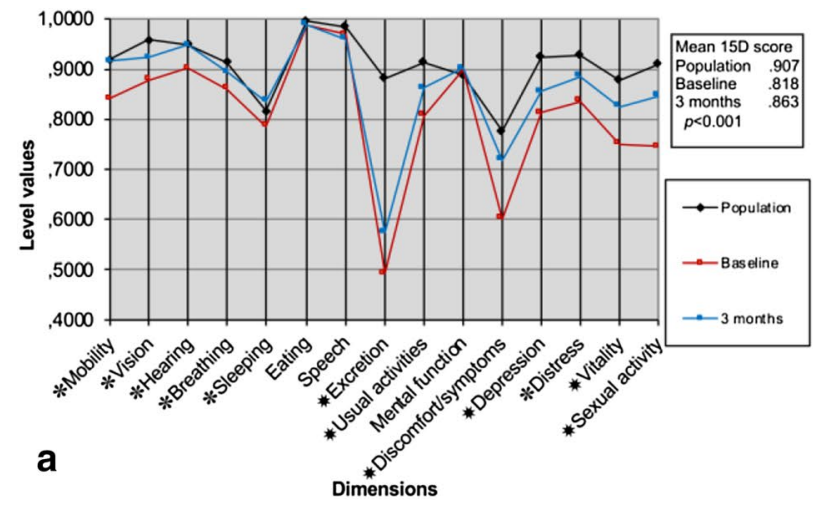

Fig. 3 HRQoL profiles of study population at baseline and at 3 and 24 months after VMR surgery vs. general population. Age and gender-adjusted 15D profiles of the patients with symptomatic posterior

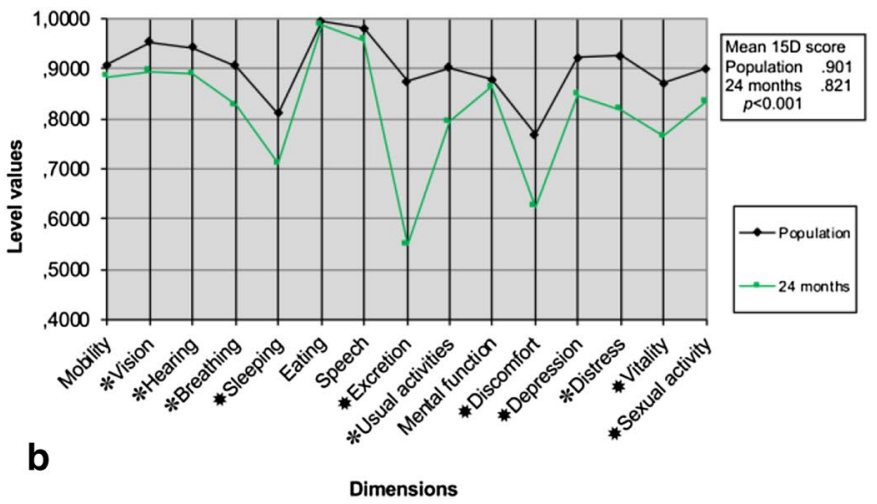

compartment procidentia in comparison to general female population $[\mathrm{H} 2000(\mathbf{a}), \mathrm{H} 2011,(\mathbf{b})] .{ }^{*} p<0.05,{ }^{*} p<0.001$

Table 3 HRQoL in the 2-year follow-up and incremental QALYs gained

\begin{tabular}{|c|c|c|c|c|c|}
\hline Surgery & $\begin{array}{l}\text { Baseline } \\
\text { Mean }(95 \% \mathrm{CI})\end{array}$ & $\begin{array}{l}3 \text { months } \\
\text { Mean }(95 \% \mathrm{CI})\end{array}$ & $\begin{array}{l}24 \text { months } \\
\text { Mean }(95 \% \mathrm{CI})\end{array}$ & Incremental QALYs & QALYs gained in 2 years \\
\hline Robotic surgery & $0.816(0.755,0.876)$ & $0.878(0.815,0.941)$ & $0.822(0.737,0.906)$ & 0.0671 (SE 0.038, SD 0.152) & $0.0454(\operatorname{SE~} 0.0483)^{\mathrm{a}}$ \\
\hline Laparoscopic surgery & $0.822(0.788,0.856)$ & $0.845(0.796,0.895)$ & $0.820(0.781,0.860)$ & 0.0217 (SE 0.026, SD 0.094) & \\
\hline
\end{tabular}

${ }^{a}$ QALYs gained using 3\% discounting was 0.0435 for 2 years and 0.104 for 5 years

+0.062 for the RVMR group and +0.023 for the LVMR group, both exceeding the minimal important change (MIC) of \pm 0.015 . At 24 months both had declined, the RVMR mean score being +0.011 and LVMR mean score being -0.003 from the baseline. The incremental QALYs gained over 2 years in favor to RVMR group was 0.0435 (SE 0.480) using 3\% discounting and 0.0454 (SE 0.0483) with no discounting (Table 3). At 24 months $87 \%$ and $69 \%$ of patients were satisfied, and $6 \%$ and $31 \%$ were dissatisfied with the end result in the RVMR and LVMR groups $(p=\mathrm{NS})$, respectively.

\section{Cost-effectiveness analysis}

The details of the surgery-related hospital costs are shown in Table 4. The RVMR was about 1.5 times more expensive than LVMR, the inflation corrected costs being $€ 5211$ for robotic and $€ 3472$ for laparoscopic operations (difference: $€ 1739$ at the 2017 price level). The costs of the operation theatre and personnel and duration of hospitalization did not differ significantly. After discharge patients in both groups had only few additional physician visits and also the sick leaves did not differ statistically significantly (RVMR 32 days vs. LVMR 36 days, $p=0.61$ ) and they were excluded from the additional analysis. The incremental cost-effectiveness ratio (ICER) for the RVMR compared to LVMR was $€ 39,982 / \mathrm{QALY}$ gained at 2 years (Table 5). Due to low QALY gain compared to baseline in the LVMR group, its cost/QALY gained was very high (over $€ 167,744$ ) and about twice the 2-year ratio of the RVMR group (€81,176).

In the sensitivity analysis we varied key cost and outcome variables in one-way and multiway analysis. In the cost estimation we tested the impact of using the observed re-surgery rate (8\% in LVMR group) which did not have any impact on the ICER. The use of $0 \%$ discount rate for QALY reduced the ICER to $€ 38,308 / \mathrm{Q} A L Y$ gained. The 5-year ICER assuming no additional surgery related costs and constant QALY gain was $€ 16,707 / \mathrm{Q} A L Y$. Decreasing the annual utilization rate from 284 to 200 patients increased the 2-year ICER to $€ 46,418 / \mathrm{Q} A L Y$ and 5-year ICER to $€ 19,397 / \mathrm{Q} A L Y$. A shorter 7-year investment period increased the above estimates about $€ 3000 / \mathrm{QALY}$ gained.

\section{Discussion}

The present study provides new data on the HRQoL and cost-effectiveness on robot-assisted ventral mesh rectopexy compared with conventional laparoscopy. Considering the commonly used "willingness to pay threshold" of $\$ 50,000$ $(€ 43,500)$, the average gains are poor for both operation methods, but the ICER for RVMR over LVMR ( $€ 39,982 /$ QALY) at 2 years is acceptable [24]. However, when we 
Table 4 Costs for the robotic and laparoscopic ventral mesh rectopexy

\begin{tabular}{|c|c|c|}
\hline Cost categories & RVMR & LVMR \\
\hline Operating theatre cost $\mathrm{t}^{\mathrm{a}}$ & 92 & 90 \\
\hline Human resources ${ }^{\mathrm{b}}$ & $373(76)$ & $376(62)$ \\
\hline \multicolumn{3}{|l|}{ Anesthesia/recovery room time } \\
\hline \multicolumn{3}{|l|}{ Instruments and disposables } \\
\hline Harmonic & - & 400 \\
\hline Disposable ports & 200 & 253 \\
\hline Protack & 195 & 195 \\
\hline Mesh & 130 & 130 \\
\hline Stitches & 45 & 45 \\
\hline Other disposables & 157.40 & 130.60 \\
\hline \multicolumn{3}{|l|}{ Use of DaVinci } \\
\hline Intuitive instruments & 1472 & \\
\hline Maintenance cost & 493 & \\
\hline \multicolumn{3}{|l|}{ Amortization } \\
\hline DaVinci $^{\mathrm{c}}$ & 637 & - \\
\hline Laparoscopic column $^{\mathrm{d}}$ & - & 18.4 \\
\hline Hospitalization $^{\mathrm{e}}$ & 1199 & 1362.5 \\
\hline Complications (re-surgery) & 120.9 & 406.1 \\
\hline Total cost in 2012 per procedure & 5114.3 & 3407.6 \\
\hline Total in 2017 prices $^{\mathrm{f}}$ & 5211.5 & 3472.3 \\
\hline
\end{tabular}

${ }^{\mathrm{a}}$ Cost for operating room usage: $0.46 € / \mathrm{min}$

${ }^{\mathrm{b}}$ Cost for operating room human resources including two surgeons and one anesthetist $(0.615 €$ per minute per capita) and three nurses $(0.21 €$ per minutes per capita)

${ }^{\mathrm{c}}$ Maintenance $140,000 € /$ year for 284 patient/year

${ }^{\mathrm{d}}$ Based on 1,625,000 $€$ investment cost, 10 years use, 284 patient/year and $2 \%$ hospital accounting interest

${ }^{\mathrm{e}}$ Based on a 47,000 $€$ investment cost, 10 years of use, 284 patients/ year and $2 \%$ hospital accounting interest

${ }^{\mathrm{f}}$ Inflation between 2012 and 2017 was 3.4\%, Statistics Finland (2018)

assumed the operative results to last for 5 years, the RVMR technique becomes more cost-effective in terms of ICER $(€ 16,707 / \mathrm{QALY})$ comparing it to the LVMR. The reinforcement to the rectovaginal septum was maintained at followup as the clinical assessment of posterior and apical compartments showed reduction of the maximal POP at strain. However, the RVMR or LVMR did not have an impact on generic HRQoL at 24-month follow-up. Despite the trend towards better function and subjective satisfaction in the RVMR group, the differences between RVMR and LVMR were statistically non-significant.

There are no previous full economic evaluations (cost-benefit, cost-effectiveness and cost-utility analyses) comparing RVMR vs. LVMR. In our study the RVMR was 1.5 times more expensive than LVMR, when operation, investment and hospitalization costs were included. In the previous studies in different indications the use of robotics have added between $€ 600-€ 5359$ per procedure to laparoscopic counterpart, but these studies have also great variation in cost-calculations, including, e.g., amortization, impact of annual case-load, and distribution of robotic use between different departments [25, 26]. A cost-analysis by Heemskerk from 2007 showed RVMR to be more expensive than LVMR, which was in part due to increased time-consumption (39 $\mathrm{min}$ ) in the RVMR [11]. Operative efficiency has been found to be essential in reducing operative cost and achieving profitability and operative time is predicting operative cost more than any other factor [27]. Statistical models have demonstrated that robotic-assisted surgery can achieve cost equivalence to laparoscopic technique, when operative times are reduced below certain levels [28]. In the rectopexy operation time does not seem to play a significant role when both operations are performed by experienced surgeons. In our study, neither operating times (RVMR $125 \mathrm{~min}$ vs. LVMR $130 \mathrm{~min}, p=0.52$ ) nor length of stay (LOS) (RVMR 2.2 days vs. LVMR 2.5 days, $p=0.71$ ) differed between the techniques. The increased costs mainly consisted of robotic investment, maintenance and instrument use.

After VMR the postoperative recovery and complications are short term measures whereas anatomic, functional and HRQoL improvements for the patient are long-term goals. The advantages of robotic-assistance in laparoscopic suturing can be hypothesized to result in more reliable mesh fixation to the rectum and apex of vagina. Recurrences have been reported to occur in 0-12.8\% after RVMR and 1.5-9.7\% after LVMR for ERP and in $10.4 \%$ after RVMR and $5.3-7.1 \%$ after LVMR for IRP $[29,30]$. One rectal prolapse recurrence and one apical descent both occurred in the LVMR group (7.7\%, $3.3 \%$ of whole cohort). However, the difference between RVMR and LVMR was not significant. The anatomical correction after RVMR and LVMR seem similar as the normal support of the posterior vaginal wall (POP-Q stage $\leq 1$ ) was maintained in all patients in both study groups in the follow-up.

The functional results showed some deterioration within time and specifically incontinence symptoms persisted. The decrease in Wexner score (mean -1.5 points RVMR and -3.4 points LVMR, $p=0.55$ ) is somewhat smaller than previously reported improvement after VMR, which may reflect to HRQoL results. The greater visibility and more precise dissection with robotic-assisted laparoscopy is proposed to be beneficial in preserving of autonomic nerves and thereby resulting in less postoperative constipation [2]. One nonrandomized study showed better improvement in obstructed defecation symptoms after RVMR compared with LVMR [31]. In the current study the reduction seen in the obstructed defecation symptoms was also in favor of RVMR $(p=\mathrm{NS})$. We observed an improvement in sexual function after rectopexy, which has also been reported previously [31]. 
Table 5 Incremental costeffectiveness analysis for 2- and 5 -year duration of surgical outcomes with and without QALYs discounted by 3\%

\begin{tabular}{lcclc}
\hline Incremental cost/QALY, Euros & 2 years & 2 years & 5 years & 5 years \\
& 0\% discount & 3\% discount & 0\% discount & 3\% discount \\
\hline Robotic & 77,784 & 81,176 & 31,076 & 33,929 \\
Laparoscopic & 160,754 & 167,744 & 64,183 & 70,006 \\
Incremental cost/QALY & 38,308 & 39,982 & 15,310 & 16,707 \\
\hline
\end{tabular}

The results of this study should be interpreted in the light of some limitations. Based on a large experimental survey, The European Union Seventh framework program recommended in 2013 that cost-effectiveness analyses should be expressed as costs per relevant clinical outcome, and QALY assessment for healthcare decision making should be abandoned due to methodological limitations of its use [32]. Although having an advantage for being relatively comparable across studies using same measures QALY is possibly not very responsive to disease-specific effects of intervention [32]. In concordance with previous reports of around $60-90 \%$ patients benefitting from the VMR $[1,2$, $5,13,29-31]$ patients were satisfied with operative result, however, 2-year HRQoL returned to baseline. In all, the HRQoL was reduced in a wide range of dimensions in this patient group both before and after operation, when compared to age-standardized general Finnish population, which may relate to a multifactorial background (Fig. 3a, b) $[33,34]$. Our results differ from the finding of a recent SF-36 HRQoL study, in which significant improvement in general health status after VMR was measured [35]. However, the symptom-specific QoL improved significantly, with PFIQ-7 combining also global pelvic floor impact. In a similar patient group of patients having an intervention for fecal incontinence, significant symptom improvement was achieved without an impact on general HRQoL [36].

The major limitation of our study is the small sample size, due to which it is underpowered to detect minor differences between the treatment groups. The study cohort may reflect the learning curve of robot operations in a single center. However, the operative outcome is comprehensively assessed by predetermined methods. The study was done using hospital perspective, i.e., not including costs and benefits for the other sectors in society. In the analysis the use of other health and social care and productivity costs between the groups were the same. It means that the societal costeffectiveness ratio that is often used in Finland would have been very similar.

The strength of this randomized study was the comprehensive evaluation of pelvic floor dysfunction in 2-year follow-up thus providing data on clinical performance of RVMR vs. LVMR and possible explanations to the HRQoL results effecting QALY. Because there was no postoperative imaging we could not rule out the possible residual IRP, which could explain symptom recurrence [37].

\section{Conclusions}

Robot-assisted ventral mesh rectopexy is more expensive than LVMR in the short-term, but incremental cost-effectiveness of RVMR may be acceptable at 2 and 5 years, suggesting this technique may offer value for money. The impact of RVMR and LVMR on long-term generic HRQoL is minor, despite symptomatic improvement. The reinforcement of the rectovaginal septum is similar in both techniques. More studies on this subject with larger cohorts with reasonable follow-up time are needed.

Acknowledgements Open access funding provided by University of Oulu including Oulu University Hospital. We thank Dr. Kai Klintrup, Dr. Heikki Takala and Dr. Mika Vierimaa for their help in operating the patients and collecting data.

Author contributions JM-K: conception and design of the study, acquisition, analysis and interpretation of data, writing the article. TR: conception and design of the study, acquisition and interpretation of data, writing the article. AO: analysis and interpretation of data, writing the article. PO: analysis and interpretation of data, writing the article, critical revision. SK: acquisition and interpretation of data, critical revision. HS: acquisition, analysis and interpretation of data, critical revision. JM: conception and design of the study, critical revision.

Funding The Gastroenterological Diseases Research Foundation, Finnish Medical Research Foundation.

\section{Compliance with ethical standards}

Conflict of interest Tero Rautio, M.D., Ph.D., is a surgical consultant for Intuitive. The other authors declare that they have no conflict of interest.

Ethical approval The study has been approved by the Ethical Committee of the Oulu University Hospital and it has been performed in accordance with the ethical standards laid down in the 1964 Declaration of Helsinki and its later amendments.

Informed consent All study participants signed a personal written informed consent.

Open Access This article is distributed under the terms of the Creative Commons Attribution 4.0 International License (http://creativeco mmons.org/licenses/by/4.0/), which permits unrestricted use, distribution, and reproduction in any medium, provided you give appropriate credit to the original author(s) and the source, provide a link to the Creative Commons license, and indicate if changes were made. 


\section{References}

1. Maggiori L, Bretagnol F, Ferron M, Panis Y (2013) Laparoscopic ventral rectopexy: a prospective long-term evaluation of functional results and quality of life. Tech Coloproctol 17:431-436

2. D'Hoore A, Cadoni R, Penninckx F (2004) Long-term outcome of laparoscopic ventral rectopexy for total rectal prolapse. Br J Surg 91:1500-1505

3. D'Hoore A, Penninckx F (2006) Laparoscopic ventral recto(colpo) pexy for rectal prolapse: surgical technique and outcome for 109 patients. Surg Endosc 20:1919-1923

4. vanIersel J, Paulides TJ, Verheijen P, Lumley JW, Broeders IA, Consten EC (2016) Current status of laparoscopic and robotic ventral mesh rectopexy for external and internal rectal prolapse. World J Gastroenterol 22:4977-4987

5. Faucheron J-L, Trilling B, Girard E, Sage P-Y, Barbois S, Reche F (2015) Anterior rectopexy for full thickness rectal prolapse: technical and functional notes. World J Gastroenterol 21:5049-5055

6. van der Schans EM, Paulides TJC, Wijffels NA, Consten ECJ (2018) Management of patients with rectal prolapse: the 2017 Dutch guidelines. Tech Coloproctol 22:589-596. https://doi. org/10.1007/s10151-018-1830-1

7. Ayav A, Bresler L, Hubert J, Brunaud L, Boissel P (2005) Roboticassisted pelvic organ prolapse surgery. Surg Endosc 19:1200-1203

8. Heemskerk J, Zandbergen R, Maesse JG, Greve JW, Bouvy ND (2006) Advantages of advanced laparoscopic systems. Surg Endosc 20:730-733

9. Baik SH (2008) Robotic colorectal surgery. Yonsei Med J 49:891-896

10. Damle A, Damle RN, Flahive JM, Schlussel AT, Davids JS, Sturrock PR, Maykel JA, Alavi K (2017) Diffusion of technology: trends in robotic-assisted colorectal surgery. Am J Surg 214:820-824

11. Heemskerk J, de Hoog D, van Gemert WG, Baeten CG, Greve JW, Bouvy MD (2007) Robot assisted vs conventional laparoscopic rectopexy for rectal prolapse: a comparative study on costs and time. Dis Colon Rectum 50:1825-1830

12. de Hoog DE, Heemskerk J (2009) Recurrence and functional results after open versus conventional versus robot-assisted laparoscopic rectopexy for rectal prolapse: a case-control study. Int J Colorectal Dis 24:1201-1206

13. Wong MTC, Meurette G, Rigaud J, Regenet N, Lehur P-A (2011) Robotic versus laparoscopic rectopexy for complex rectocele: a prospective comparison of short-term outcomes. Dis Colon Rectum 54:342-346

14. Rondelli F, Bugiantella W, Villa F, Sanguinetti A, Boni M, Mariani Avenia N (2014) Robot-assisted or conventional laparoscopic rectopexy for rectal prolapse? Systematic review and meta-analysis. Int J Surg 12:S153-S159

15. Mäkelä-Kaikkonen J, Rautio T, Koivurova S, Pääkkö E, Ohtonen P, Biancari F, Mäkelä JT (2016) Anatomical and functional changes to the pelvic floor after robotic versus laparoscopic ventral rectopexy: a randomised study. Int J Urogynecol 27:1837-1845

16. Mäkelä-Kaikkonen J, Rautio T, Klintrup K et al (2014) Roboticassisted and laparoscopic ventral rectopexy in the treatment of rectal prolapse: a matched-pairs study of operative details and complications. Tech Coloproctol 18:151-1535

17. Sintonen H (2001) The $15 D$ instrument of health-related quality of life: properties and applications. Ann Med 33:328-336

18. Barber MD, Walters MD, Bump RC (2005) Short forms of two condition specific questionnaires for women with pelvic floor disorders (PFDI-20 and PFIQ-7). Am J Obstet Gynecol 193:103-1513

19. Jorge JMN, Wexner SD (1993) Etiology and management of fecal incontinence. Dis Colon Rectum 36:77-97

20. Altomare DF, Spazzafumo L, Rinaldi M, Dodi G, Ghiselli R, Piloni V (2009) Set-up and statistical validation of a new scoring system for obstructed defecation syndrome. Dis Colon Rectum 52:592-597

21. Bump R, Mattiasson A, Bo K, Brubaker L, DeLancey JOL, Klarskov P, Shull BL, Smith ARB (1996) The standardization of terminology of female pelvic organ dysfunction. Am J Obstet Gynecol 175:10-17

22. Official Statistics of Finland 2018. http://www.tilastokeskus.fi. Accessed May 2018

23. Drummond M, Sculpher M, O'Brien B, Stoddard G, Torrance G (2015) Methods for the economic evaluation of health care programs, 4th edn. Oxford University Press, Oxford

24. Grosse SD (2008) Assessing cost-effectiveness in healthcare: history of the 50,000 per QALY threshold. Expert Rev Pharmacoecon Outcomes Res 8(2):165-178. https://doi.org/10.1586/14737 167.8.2.165

25. Heemskerk J, Bouvy D, Baeten CG (2014) The end of robotassisted laparoscopy? A critical appraisal of scientific evidence on the use of robot-assisted laparoscopic surgery. Surg Endosc 28:1388-1398

26. Faucheron JL, Trilling B, Barbois S, Sage PY, Waroquet PA, Reche F (2016) Day-case robotic ventral rectopexy compared with day case laparoscopic ventral rectopexy: a prospective study. Tech Coloproctol 20:695-700

27. Geller E, Matthews CA (2013) Impact of robotic operative efficiency on profitability. Am J Obstet Gynecol 209:20.e1-20.e5

28. Judd J, Siddiqui NY, Barnett JC, Visco AG, Havrilesky LJ, Wu JM (2010) Cost-minimization analysis of robotic-assisted, laparoscopic, and abdominal sacrocolpopexy. J Minim Invas Gynecol 17:493-499

29. Consten EC, van Iersel JJ, Verheijen PM, Broeders IA, Wolthuis AM, D'Hoore A (2015) Long-term outcome after laparoscopic ventral mesh rectopexy: an observational study of 919 consecutive patients. Ann Surg 262(5):742-747

30. van Iersel JJ, Paulides TJ, Verheijen PM, Lumley JW, Broeders IA, Consten EC (2016) Current status of laparoscopic and robotic ventral mesh rectopexy for external and internal rectal prolapse. World J Gastroenterol 22(21):4977-4987

31. Mantoo S, Podevin J, Regenet N, Rigaud J, Lehur P-S, Meurette M (2013) Is robotic-assisted ventral mesh rectopexy superior to laparoscopic ventral mesh rectopexy in the management of obstructed defaecation? Colorectal Dis 15:469-475

32. Beresniak A, Medina-Lara A, Auray JP, De Wever A, Praet JC, Tarricone R, Torbica A, Dupont D, Lamure M, Duru G (2015) Validation of the underlying assumptions of the quality-adjusted life-years outcome: results from the ECHOUTCOME European project. Pharmcoeconomics 33:61-639

33. Aromaa A, Koskinen S (2004) Health and functional capacity in Finland. Baseline results of the Health 2000 Health Examination Survey. Publications of the National Public Health Institute B21/2004. http://www.julkari.fi. Accessed 2004

34. Koskinen S, Lundqvist A, Ristiluoma N (eds.) (2012) Health, functional capacity and welfare in Finland in 2011. National Institute for Health and Welfare (THL), Report 68/2012. http://julka ri.fi. Accessed 11 Nov 2012

35. Tsunoda A, Takahashi T, Ohta T, Kusanagi H (2016) Quality of life after laparoscopic ventral rectopexy. Colorectal Dis 18:301-310

36. Ratto C, Buntzen S, Aigner F, Altomare DF, Heydari A, Donisi L, Lundby L, Parello A (2016) Multicentre observational study of the Gatekeeper for faecal incontinence. Br J Surg 103:290-299

37. Tsunoda A, Takahashi T, Ohta T, Fujii W, Kusanagi H (2016) New-onset rectoanal intussusception may not result in symptomatic improvement after laparoscopic ventral rectopexy for external rectal prolapse. Tech Coloproctol 20:101-107

Publisher's Note Springer Nature remains neutral with regard to jurisdictional claims in published maps and institutional affiliations. 